\title{
Endoscopic ultrasound-guided placement of biliary lumen-apposing metal stent through a duodenal stent
}

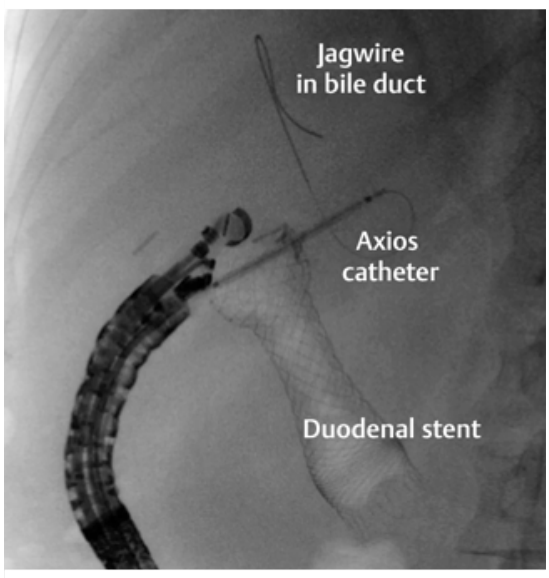

- Fig. 1 AXIOS catheter through a duodenal stent, fluoroscopic view.

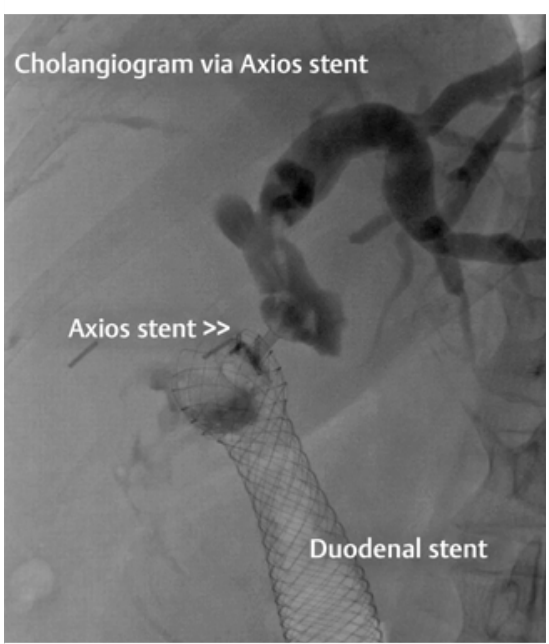

- Fig. 2 Cholangiogram via lumen-apposing metal stent, placed through duodenal stent.

Endoscopic management of a malignant biliary obstruction becomes a significant challenge in the setting of an existing duodenal stent [1]. Progressive malignancy often causes stenosis of the duodenal stent, which renders it impassable by a duodenoscope. Options for biliary decompression include percutaneous drainage or endoscopic ultrasound (EUS)-guided choledochoduodenostomy or hepaticogastrostomy. We describe the

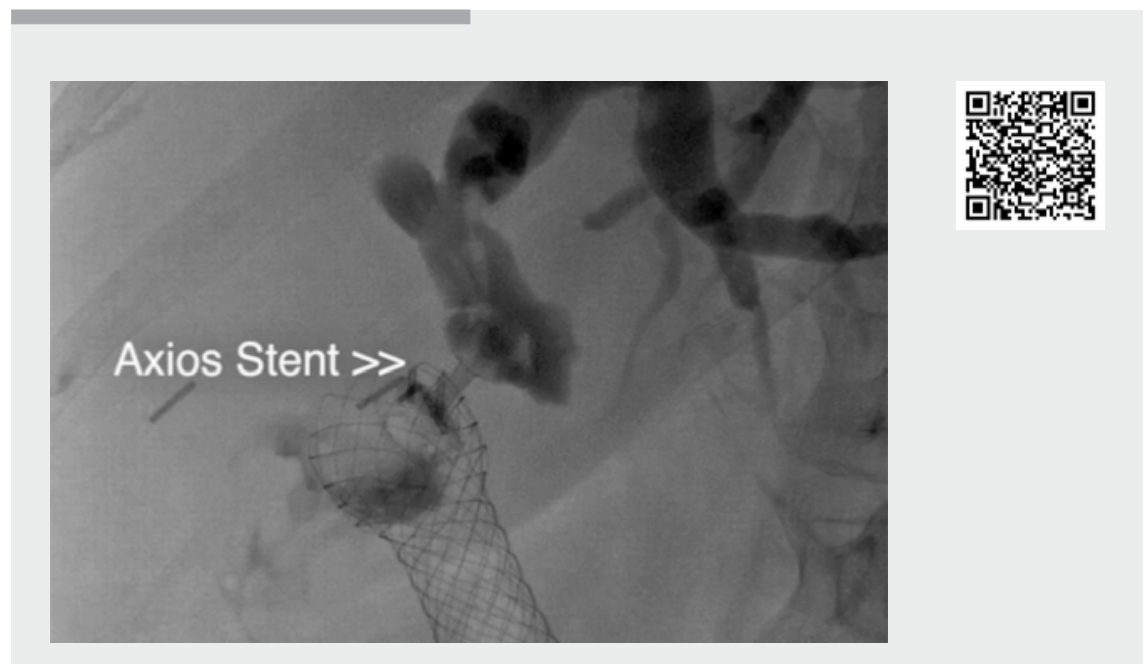

Video 1 Electronic ultrasound-guided placement of biliary lumen-apposing stent through a duodenal stent.

case of an EUS-guided choledochoduodenostomy using a lumen-apposing metal stent (LAMS) through the struts of an existing duodenal stent $(\triangleright$ Video 1$)$.

A 61-year-old woman with a pancreatic mass and obstructive jaundice had a covered metal stent placed at endoscopic retrograde cholangiopancreatography (ERCP). Unresectable pancreatic adenocarcinoma was subsequently confirmed, and she underwent chemotherapy. She eventually developed a gastric outlet obstruction related to duodenal stenosis. A duodenal stent was placed. During enteral stent placement, the existing covered biliary stent migrated out of the bile duct. The ampulla was not accessible via the enteral stent. The patient redeveloped obstructive jaundice, and options for drainage in the setting of the duodenal stent were discussed. The patient preferred EUS-guided choledochoduodenostomy.

The proximal end of the enteral stent was seated within the duodenal bulb. For visualization of the bile duct, the echoendoscope was placed into the proximal end of the stent. The bile duct measured $18 \mathrm{~mm}$. The stent caused significant artefacts that made visualization of the bile duct challenging. Electrocautery (pure cut, 100 W) was used and an $8-\mathrm{mm} \times 8-\mathrm{mm}$ LAMS (Hot AXIOS) was placed through the proximal struts of the enteral stent into the bile duct. A 0.035 -in guidewire was placed to secure the position ( $>$ Fig. 1). A combination of sonographic, direct, and fluoroscopic guidance was used to deploy the stent. Immediate biliary drainage was noted. A cholangiogram performed via the LAMS confirmed adequate stent position ( Fig.2). The patient was discharged for ongoing palliative care two days later. Her biliary obstruction improved, however she died of advanced disease two months later.

Endoscopy_UCTN_Code_TTT_1AS_2AD

\section{Competing interests}

The authors declare that they have no conflict of interest. 
The authors

Jawad Rasool, Carthage Moran, Danny

Cheriyan

Department of Gastroenterology, Beaumont

Hospital, Dublin, Ireland

Corresponding author

Danny Cheriyan, MD

Department of Gastroenterology, Beaumont Hospital, Dublin 9, Ireland

Fax: +353018098090

dgcheriyan@gmail.com

\section{Reference}

[1] Yamao K, Kitano M, Takenaka M et al. Outcomes of endoscopic biliary drainage in pancreatic cancer patients with an indwelling gastroduodenal stent: a multicenter cohort study in West Japan. Gastrointest Endosc 2018; 88: 66-75

\section{Bibliography}

Endoscopy 2021; 53: E116-E117

DOI 10.1055/a-1187-0869

ISSN 0013-726X

published online 24.7.2020

(c) 2020. Thieme. All rights reserved.

Georg Thieme Verlag KG, Rüdigerstraße 14, 70469 Stuttgart, Germany
ENDOSCOPY E-VIDEOS

https://eref.thieme.de/e-videos

口回 Endoscopy E-Videos is a free access online section, reporting 回舴: on interesting cases and new techniques in gastroenterological endoscopy. All papers include a high quality video and all contributions are freely accessible online.

This section has its own submission website at

https://mc.manuscriptcentral.com/e-videos 